\title{
Some Thoughts on Entrepreneurship Education in Chinese Colleges and Universities
}

\author{
Kai Hou*, Meixiang La \\ College of Agricultural Economics and Management, Shanxi Agricultural University, Taiyuan 030031, China \\ "Corresponding author. Email: 2419719067@qq.com
}

\begin{abstract}
In recent years, Chinese institutions of higher learning actively carry out entrepreneurship education, but there is still a certain gap compared with the international leading countries in entrepreneurship education. In order to provide inspiration for the development of entrepreneurship education in China, this paper investigates the advanced entrepreneurship education in foreign countries and the practice of entrepreneurship education in China, and draws relevant thoughts from the comparison: Strengthen formal entrepreneurship education; To develop entrepreneurial theories suitable for China; Make entrepreneurship credit strict; Strengthen postgraduate entrepreneurship education; Set up business incubators in core cities.
\end{abstract}

Keywords: Entrepreneurship education, Institutions of higher learning, Business Incubator.

\section{PROMOTE FORMAL ENTREPRENEURSHIPEDUCATION}

In recent years, as the country advocates mass entrepreneurship and innovation, a strong entrepreneurial atmosphere has formed in the society. In addition, emerging technologies, especially Internet-related technologies, have been widely applied, from sharing economy to artificial intelligence, giving rise to a wave of entrepreneurship. As energetic young people, college students not only master advanced scientific and technological knowledge, but also have the spirit of daring to break new ground. Naturally, they are very active in the entrepreneurial wave. There are also many start-up competitions on campus and in society for college students.

Although a lot of college students succeed in starting their own businesses, there are also many who fail to do so. Zhejiang Province (a coastal province with developed economy and strong business atmosphere) has a high success rate of college students' starting their own businesses, but it is still less than $10 \%$, which is far behind the $20 \%$ success rate in developed countries in Europe and America. Mao Kankan, a youth entrepreneur idol, committed suicide due to entrepreneurial setbacks, which has aroused widespread social concern. At present, the success rate of college students' entrepreneurship is relatively low (less than $10 \%)$. On the one hand, the market is full of so-called success books with deceptions and inductions, which have a negative impact on college students. On the other hand, there are insufficient systematic and rational entrepreneurship courses in colleges and universities, which makes it difficult for college students to get a correct understanding of entrepreneurship. This fully shows that entrepreneurship education for college students needs to be further strengthened and deepened. Only more fully carried out entrepreneurship education can effectively improve the entrepreneurial ability of college students, increase the success rate of their entrepreneurship, improve their self-confidence in entrepreneurship, and avoid the waste of social resources. In order to prevent the similar tragedy of Mao Kankan from happening again, it is necessary to guide college students correctly through entrepreneurship education. Even if college students encounter temporary setbacks in the process of entrepreneurship, they can actively learn from the experience and lessons, treat rationally, and lay a good foundation for the success of entrepreneurship in the future.

The real world is often a painful scene: a large number of informal entrepreneurship training centers and institutions that charge high fees to college students eager to acquire knowledge about entrepreneurship, But it is the mobsters and even the charlatans who serve as the so-called mentors, offering the so-called entrepreneurship courses that are miscellany and of no nutritional value, —-It is conceivable that this will 
only have a negative impact on enthusiastic, naive young students who lack social experience. The cheated college student then takes the hard-earned money from his parents and sets up a company with a fancy name (like Block-chain or Financial Innovation), what it really is that he even probably doesn't know himself. Then they go to all kinds of startup competitions, and they go around making fancy PowerPoint presentations. As you can imagine, this has no practical effect. Under the adverse influence of utilitarianism, college students fantasize about getting huge investment and realizing financial freedom, but over the years, they themselves become victims unwittingly.

The cold numbers reflect the cruel reality. In 2017, more than 200,000 college students started their own businesses in China, and the success rate was only $3 \%$, Zhejiang Province slightly higher, which was only 5\%, significantly lower than the $20 \%$ success rate of college students in developed countries in Europe and America. Is the ability of our university students themselves congenital deficiency? No! This is just from another side reflected the informal so-called entrepreneurship training in the society, extremely shoddy, has produced a huge adverse impact. Formal entrepreneurship education is an important bridge for college students to acquire complete and systematic entrepreneurship knowledge and cultivate their own entrepreneur quality. Many studies have shown that formal entrepreneurship education has a positive impact on improving the success rate of college students' entrepreneurship. Entrepreneurship education in American colleges and universities has a history of more than 60 years, and its basic theories and research achievements are very rich. As early as 2005, more than 1,600 institutions of higher learning in the United States offered formal entrepreneurship courses, carried out academic research related to entrepreneurship education, set up research institutions on entrepreneurship education, and published more than 40 academic journals on entrepreneurship education. Under the background of "the unprecedented changes in a century and the development of a new type of relations between great powers", the formal entrepreneurship education in Chinese colleges and universities is in urgent need of strengthening, compared with that in the United States.

\section{DEVELOP ENTREPRENEURIAL THEORIES SUITABLE FOR THE CHINESE CONTEXT}

Innovation-driven development is an important development strategy for China at present and for a period to come. As a developing country and an emerging economy, successfully leapfrog the middle-income trap, catch up with and gradually surpass advanced economies, and an important path to shift from extensive development driven by factors to high-quality development (Through Schumpeterian creative destruction). As a country with a long history and ancient civilization, China has its own unique culture, system and tradition, which are totally different from Western countries. These unique Chinese institutional-cultural factors are bound to be reflected and acted in the Chinese market, On the one hand, the socialist market economy of China has the abstract characteristics of the western neo-classical theory of market economy, and on the other hand, it has distinctive Chinese characteristics. At present, China's entrepreneurial theories are mostly mature theories directly introduced from western developed countries. First of all, these theories were formed more than ten or even decades ago. It is not necessarily suitable for the current and future period of continuous development of information technology and the development trend of the tide of artificial intelligence, the theory itself needs to be further deepened and improved. More importantly, these entrepreneurial theories directly borrowed from the West may not be suitable for China's national conditions.

Many scholars in the field of entrepreneurship realize that the actual entrepreneurial process is embedded in the specific context and context of the real world, Context is a general term, including objective environment, existing conditions, facing the situation, natural environment and other real situations. China is on a great journey to realize the Chinese Dream and national renewal. A splendid cultural heritage, the transformational dynamism of emerging economies, and a unified, complete and large domestic market all combine to create a unique context for China. Contextualized entrepreneurship research needs to play a more important role in entrepreneurship theory, so it is urgent to develop contextualized and local theories suitable for China's specific national conditions on the basis of the existing mature entrepreneurship theories in the West. Only by forming a perfect theory of entrepreneurship based on Chinese context can we better guide the practice of entrepreneurship in China.

\section{BETTER NOT TO IMPLEMENT THE ENTREPRENEURIAL CREDIT SUBSTITUTION SYSTEM}

South Korea, an East Asian country, has been strongly supporting entrepreneurship education in higher education institutions since the 1990s. The government and education authorities of South Korea have developed a series of projects, such as the five-year plan for entrepreneurship education in universities and the training plan for pioneering universities, to support key universities to carry out entrepreneurship education. Among them, Hanyang University, Chungbuk University and Korea Advanced Institute of Science and Technology are more prominent institutions of higher learning to carry out entrepreneurship education. 
Hanyang University is located in the Capital Economic Circle of South Korea, with a superior geographical location. The Capital Economic Circle of South Korea has a high level of economic development, a strong business atmosphere and very active entrepreneurial behaviors. It can be said that Hanyang University is immersed in the superior entrepreneurial environment, so Hanyang University has become the most active university for entrepreneurship education in South Korea. Hanyang University has perfect and rich entrepreneurship education courses. On the one hand, Hanyang University has absorbed sufficient nutrients from the rich entrepreneurial soil in the Capital Economic Circle; on the other hand, the entrepreneurship education of Hanyang University has stimulated and promoted the entrepreneurial behaviors of college graduates and deepened the entrepreneurial atmosphere in the Capital Economic Circle. The two have formed a benign interaction. Chungbuk University is a local national university in South Korea. It focuses on strengthening its entrepreneurship education courses in combination with regional characteristics, aiming to cultivate innovative talents suitable for local economic and social development with students as the center. Korea Advanced Institute of Science and Technology is South Korea's top university, the world famous research universities, It not only carries out entrepreneurship education courses throughout the school, but also breaks the boundary of the campus and promotes its in-depth entrepreneurship education courses to the society, so as to provide high-quality entrepreneurship education content for people who are eager for innovation and entrepreneurship in the society.

It is worth noting that in recent years, some universities in China have advocated the implementation of "credit substitution system for entrepreneurship" in order to encourage college students to accept entrepreneurship education. On the issue of credit substitution, typical universities in South Korea have different practices. Hanyang University implements the substitute-credit system for entrepreneurship, while Chungbuk University holds a conservative attitude towards the substitute-credit system for entrepreneurship. Korea Advanced Institute of Science and Technology, the country's top university with the highest entrepreneurship education level, does not implement the substitute-credit system for entrepreneurship. It can be seen that the level of entrepreneurship education is not necessarily related to the credit substitution system. This paper argues that the entrepreneurial credit substitution system should not be implemented or at least should be taken at a very cautious attitude. If entrepreneurship credits can substitute credits in other subjects, although it will induce students who do not work hard and do not study seriously in other subjects to passively accept entrepreneurship education, but if these students don't study hard in other subjects, how can they take entrepreneurship education seriously? Their purpose of receiving entrepreneurship education is probably just to get credits, rather than to really improve their entrepreneurial ability. It undermines academic seriousness, and is unfair to other disciplines, and gives entrepreneurship education itself a bad name (it just takes in students who are struggling in other disciplines to get credits here easily). It's not necessarily going to have a good effect. Therefore, this paper believes that students who receive entrepreneurship education can and should get entrepreneurship credits honestly. Entrepreneurship credits no need and should not be used to substitute other credits, so as to better preserve the dignity of universities and academia itself.

\section{EXTEND ENTREPRENEURSHIP EDUCATION TO POSTGRADUATE LEVEL}

Finland, a Nordic country, has carried out entrepreneurship training since the 1980s and gradually formed a systematic entrepreneurship education system since the 1990s. Entrepreneurship education in Finland believes that it is difficult to acquire entrepreneurial skills and entrepreneurship in the stage of higher education overnight, so its entrepreneurship education extends to the stage of basic education. In contrast, in China, students face great pressure in the stage of basic education in order to enter a higher school. At this stage there is fierce competition and almost no entrepreneurship education. The lack of entrepreneurship education in basic stage makes it more difficult to achieve the goal of entrepreneurship education in higher stage.

With a history of more than 70 years, entrepreneurship education in the United States has formed a coherent and complete system from elementary and middle school level to undergraduate level and then to graduate student level. Their entrepreneurship education in colleges and universities not only covers undergraduate level, but also extends to master and doctoral level. Entrepreneurship education in the United States has achieved comprehensive coverage of undergraduate education, graduate education, continuing education and adult education at different levels. Entrepreneurship education in Australian universities has also achieved full penetration of all stages from admission to graduation. With full coverage of students' academic career, the university students can learn entrepreneurship courses and receive entrepreneurship education at any grade and academic level. In recent years, China's institutions of higher learning are also trying their best to promote entrepreneurship education, but the coverage still needs to be further improved. 
Entrepreneurship education in many countries focuses on the full coverage of all students, from the lower grade to the higher grade. However, taking a university in North China as an example, its entrepreneurship education is mainly aimed at undergraduates. For freshmen, a compulsory course on the basis of entrepreneurship is offered, and then students who are interested in entrepreneurship can continue to attend the Pioneer Entrepreneurship class. In this case, the degree of integration of professional education and entrepreneurship education is low, because freshmen do not involve in many professional courses. They mainly study public courses and basic courses in the first year, so they do not have a deep understanding and experience of the major they learn. In the second and third grades, if students do not actively participate in entrepreneurial practice, the basic knowledge they learned in the first year of entrepreneurship is likely to be forgotten, difficult to play a due effect. Extending entrepreneurship education to graduate level can further deepen the integration of professional education and entrepreneurship education. Because first of all, after four years of professional learning and professional review for the postgraduate entrance examination, postgraduates have higher professional standards than undergraduates; Secondly, postgraduate students can choose the majors they are more interested in when take the examination, and their interests are more closely matched with the majors they study. Therefore, it is very necessary to carry out entrepreneurship education at the postgraduate level, which is more in line with the principle of the integration of professional education and entrepreneurship education, as well as the principle of full coverage. At the same time, it is necessary to expand the coverage of small-class teaching of entrepreneurship education, establish academic research institutions for entrepreneurship, and grasp the latest research results and the international academic frontier in the field of entrepreneurship.

\section{SET UP UNIVERSITY BUSINESS INCUBATORS IN CORE CITIES}

When some scholars measure entrepreneurial activity, they use the number of new market entities per 10,000 people to measure it. The results show that the southeast coastal provinces, Zhejiang, Jiangsu, Guangdong, Fujian and Hainan(as a free trade port), have high entrepreneurial activity. Inland provinces in central and western China have low entrepreneurial activity. Venture capital is also mainly invested in Jiangsu, Zhejiang, Guangdong, Shanghai and other economically developed provinces. The funds were mainly invested in areas such as the Internet and high-end services, while only a small amount was invested in agriculture, forestry, animal husbandry and fishery. As of 2018, there are 12,000 business incubators in China, and business incubators are mainly densely distributed in the core cities of metropolitan areas.

Mainstream academic studies mostly endorse the entrepreneurial ecosystem holism view, holistic view holds that entrepreneurial ecosystem is a unified whole composed of entrepreneurial enterprises, universities and research institutions, government, business incubators, investment institutions and entrepreneurial environment, with obvious regional and symbiotic characteristics. The entrepreneurship education of the University of Sydney is mainly undertaken by the Business School of the University. The steady development of the business incubator of the University of Sydney not only benefits from the brand value of the University itself, but also cannot do without the unique advantages of Sydney, an international metropolis. When individuals make career choices (whether to start a business or not), they will be affected by the greater environment they perceive. The more prosperous the regional economic development is, the more entrepreneurial opportunities will be generated, which will improve the entrepreneurial willingness of individuals and promote the actual occurrence of entrepreneurial behaviors. In big cities, information, capital and talents are fully gathered, and there are more potential entrepreneurial opportunities. Entrepreneurial service institutions such as business incubators need to effectively integrate various elements such as finance, technology, professional services and human resources, so that they can truly become an important force to facilitate entrepreneurship.

Taking an agricultural university in central China as an example, its business incubator is located in a small county, far away from the core city. Little venture capital was invested in the agricultural field, and it was more difficult for university business incubators which set up in small counties to gather enough financial elements. If business incubators are set up in core cities (provincial capitals are also core cities in metropolitan areas), they will be close to financial streets where financial institutions gather, which is conducive to the integration of capital elements and the full play of the role of business incubation. At the same time, China's college graduates will reach 9 million in 2021, and there is an urgent need to promote employment through entrepreneurship to ensure the bottom line of employment. If the business incubator is located in a small county, it can only serve the students of one school, and even the students of that school go to different parts of the country after graduation, the employment promotion effect is limited. If the business incubator is located in the provincial capital city, it will not only serve the students of one university, but also expand the service scope for more college graduates in the provincial capital city. To attract more college students in the province who are interested in 
participating in the cause of rural revitalization to start businesses and get jobs in the fields of agriculture, so as to effectively play and amplify the effect of entrepreneurship and employment.

\section{CONCLUSION}

This paper investigates the advanced entrepreneurship education in foreign countries and the practice of entrepreneurship education in China, and draws relevant thoughts from the comparison: Strengthen formal entrepreneurship education; To develop entrepreneurial theories suitable for China; Make entrepreneurship credit strict; Strengthen postgraduate entrepreneurship education; Set up business incubators in core cities.

\section{REFERENCES}

[1] Baron, A. (1998). Cognitive mechanisms in entrepreneurship: why and when entrepreneurs think differently than other people. Journal of Business Venturing, 13, 275-294.

[2] C. Mirjam van Praag, \& Versloot, P. H. (2007). What is the value of entrepreneurship? A review of recent research. Small Business Economics, 29(4), $351-382$

[3] Davidsson, P.,\& Wiklund, J. (1999). Suitable approaches for studying small firm growth: the role of entrepreneurship and small and medium enterprises. In Proceedings of the 44th ICSB World Conference, June 2-23, Italy

[4] European Commission.(2006). Entrepreneurship education in Europe: fostering entrepreneurial mindsets through education and learning. In: Final Proceedings of the Conference on Entrepreneurship Education in Oslo. 